\title{
Comment: Relevance of sonography for botulinum toxin treatment of cervical dystonia: An expert recommendation
}

\author{
Wolfgang $\mathrm{H}$ Jost
}

Department of Neurology, University of Freiburg, Germany

\section{Article Info}

\section{Article Notes}

Received: 18/04/2016

Accepted: 03/05/2016

\section{Correspondence:}

Prof. Wolfgang $\mathrm{H}$ Jost

Department of Neurology

University of Freiburg

Breisacher Str. 64, 79106, Freiburg, Germany

Email: wolfgang.jost@uniklinik-freiburg.de

(c) 2016 Jost WH. This article is distributed under the terms of the Creative Commons Attribution 4.0 International License.

\section{Keywords}

Botulinum Toxin

Cervical Dystonia

Electromyography

Sonography

\begin{abstract}
For years we have been injecting botulinum toxin relying mainly on our clinical experience and, in some cases, on the use of electromyography. Within that time some therapists introduced sonography for guidance and emphasize the advantages of this technique. Schramm et al., for example, pointed out the relevance of sonography for botulinum toxin treatment in cervical dystonia. Within a short time the importance of sonography has been well documented in this indication. Even assuming a critical distance, the significance of this technique has become largely indisputable.
\end{abstract}


Injection of botulinum toxin has been the therapy of choice in cervical dystonia since the late $1980^{\prime} \mathrm{s}^{1}$. In the beginning only a few muscles were injected, based not on scientific examination, but rather on clinical experience ${ }^{2}$. We were convinced that our clinical experience and anatomical ideas were sufficiently reliable. The results in fact exceeded our expectations and confirmed our recommendations. Only in difficult cases did we apply electromyography (EMG) to detect the relevant muscles ${ }^{3}$. At that time we still believed that we were sufficiently able to differentiate muscles with EMG. We did not yet realize how difficult it is to discriminate the muscles of the neck precisely, and that in cervical dystonia there are several muscles involved which are not really relevant in normal (physiologic) conditions. Due to the facts that electrophysiologists are not only familiar with the technique, but also experienced with insertion of needles into deep muscles, they very often were willing to treat cervical dystonia with botulinum toxin.

It is indisputable that with a careful clinical examination we are able to define the muscles responsible for abnormal posture and movement, and to differentiate between agonistic and antagonistic muscles. The next step is to inject into the right muscles. Clinical experience and even published data demonstrates, that the outcome is poorer than mentioned.

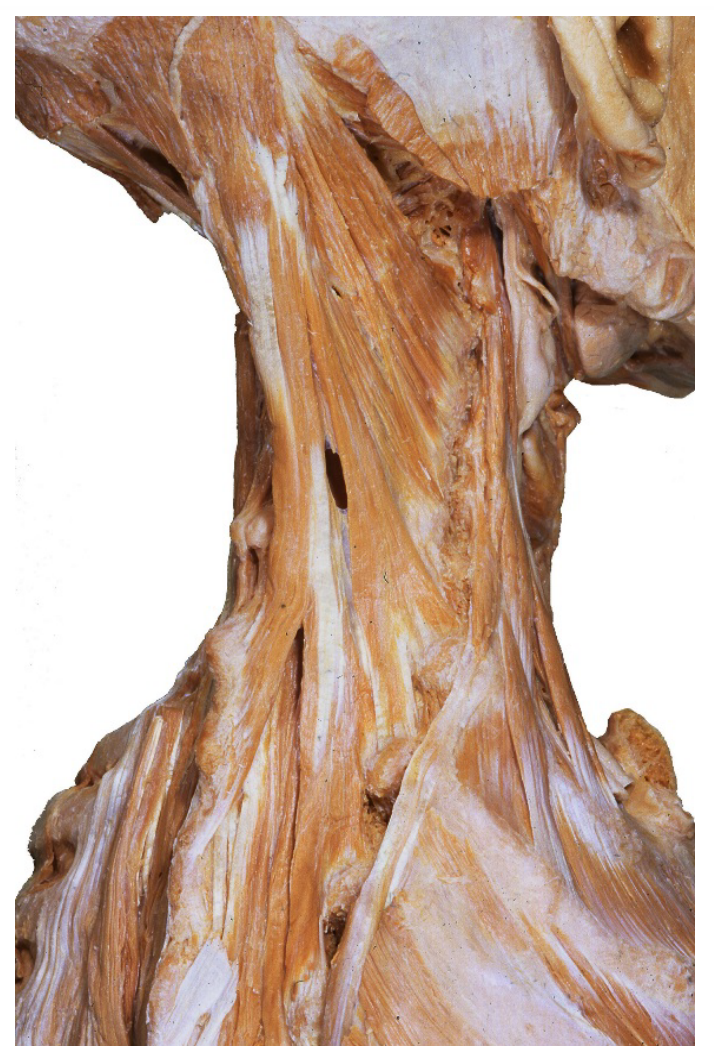

Figure 1: Anatomical preparation of neck muscles (corpsus). CProf. L.Tatu, Department of Anatomy, Besançon, France

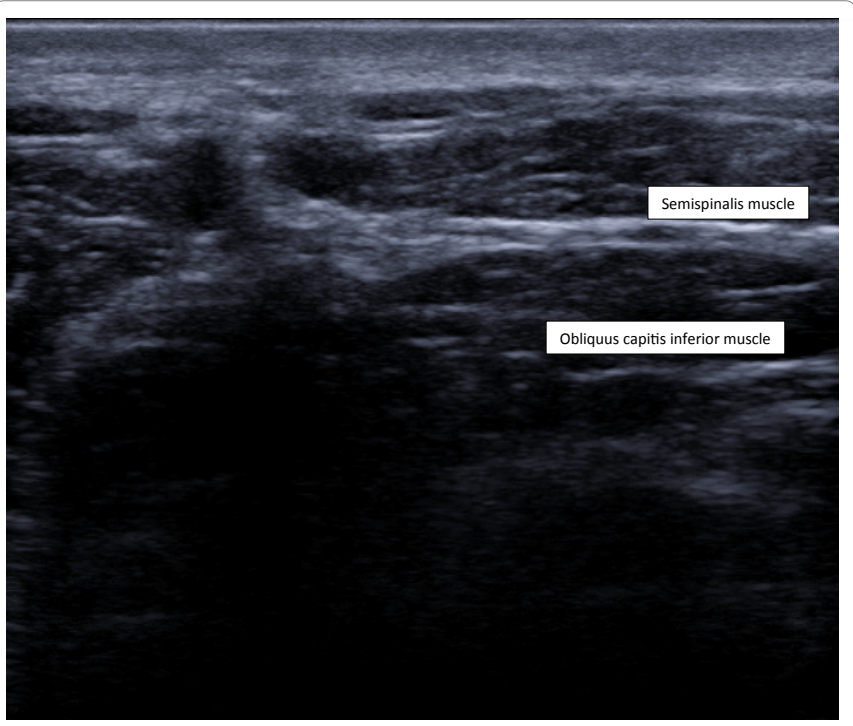

Figure 2: Sonography at level $\mathrm{C} 2, \mathrm{OCl}$ at a depth of 1.5 to $2 \mathrm{~cm}$ (below semispinalis muscle)

Aftersomeunexpected experiencewithpoorresponders, we have since learned that some assumptions were false and even harmful ${ }^{4}$. Working on corpses we demonstrated that the size of the muscles was in fact different from what we expected: E.g., trapezius or even splenius capitis were only a matter of millimeters deep (Figure 1). By extensively reviewing basic anatomical and physiological data we concluded that, for example, sternocleidomastoid muscle does not turn the neck in torticollis (because of insertion at the processus mastoideus and linea nuchalis superior, not at the processus transversus or spinosus), and therefore is neither a key muscle, nor to be injected in torticollis, but in torticaput ${ }^{4,5}$. With this new realization on the colcap classification, we identified new key-muscles such as the levator scapulae, and established the importance of some deep muscles such as the obliquus capitis inferior (OCI) muscle ${ }^{4,5}$. Next we had to realize that sometimes these "deep" muscles were not deep at all, e.g. the OCI is sometimes only $1.5 \mathrm{~cm}$ deep (Figure 2), and we were very often therefore in fact injecting into these muscles without realizing it. Another important fact is that the new generation of neurologists is more likely to be experienced with ultrasound rather than with electromyography.

Therefore, a number of authors discussed the relevance of sonography in the therapy of cervical dystonia ${ }^{6}$. They did this quite cautiously, as they were quite aware of the reservations of most experts in this field. In the long run I now believe that in a few years nobody will challenge the use of sonography in the treatment with botulinum toxin any more. It will not only be a useful tool, but indispensible.

As a case in point, we are not able to differentiate splenius capitis and semispinalis at level C4 precisely without sonography. The muscles are thinner than 
anticipated, and it is not possible to inject the full volume in the proper place. If one does not use sonography one may inject too deeply (meaning outside) or in the middle of the two bellies of the SCM, and not in the muscle itself. We were not able to target precisely the OCI clinically, or to identify different parts of the levator scapulae muscle, or to distinguish the splenius capitis muscle from the splenius cervicis muscle. Using sonography we are able to depict the plexus and to inject the scalene muscles without any harm or side effects. ${ }^{6}$

With a little experience one may well use sonography as a helpful tool. It is not more time consuming than without, but in fact rather less time consuming (in connection time), painful (due to the size of the needle) and costly (using a special needle) than EMG. Side effects will be less often ${ }^{7}$. If one needs functional information, one may combine sonography with EMG (sonography provides morphology, EMG information about function). For therapy of spasticity in childhood, sonography is in the meantime vital, and for therapy of spasticity in adults sonography is becoming more and more important. For therapy of cervical dystonia sonography will become very important within the next few years, and looking back it will seem hard to believe that there had been a time when we were arguing for its necessity.

\section{References}

1. Tsui JK, Eisen A, Mak E, Carruthers J, Scott A, Calne DB. A pilot study on the use of botulinum toxin in spasmodic torticollis. Can J Neurol Sci 1985; 12 (4): 314-316.

2. Jankovic J, Schwartz K. Botulinum toxin injections for cervical dystonia. Neurology 1990; 40(2): 277-280.

3. Nijmeijer SW, Koelman JH, Kamphuis DJ, Tijssen MA. Muscle selection for treatment of cervical dystonia with botulinum toxin--a systematic review. Parkinsonsim Relat Disord 2012; 18(6): 731-736.

4. Reichel G. Cervical dystonia: a new phenomenological classification for botulinum toxin therapy. Basal Ganglia 2011; 1: 5-12.

5. Jost WH, Tatu L. Selection of muscles for botulinum toxin injections in cervical dystonia. Mov Disord Clin Pract 2015; 2 (3): 224-226.

6. Schramm A, Bäumer T, Fietzek U, Heitmann S, Walter U, Jost WH. Relevance of sonography for botulinum toxin treatment of cervical dystonia - an expert recommendation. J Neural Transm 2015; 122 (10): 1457-1463.

7. Hong JS, Sathe GG, Niyonkuru C, Munin MC. Elimination of dysphagia using ultrasound guidance for botulinum toxin injections in cervical dystonia. Muscle Nerve 2012; 46 (4): 535-539. 